\title{
Cadaveric Arterial Graft
}

National Cancer Institute

\section{Source}

National Cancer Institute. Cadaveric Arterial Graft. NCI Thesaurus. Code C117819.

An arterial graft harvested from a cadaver. 